\title{
Bid based Power Flow for Practical Utility System
}

\author{
C.Venkatesan \\ Assistant Professor/EEE \\ V.R.S College of Engineering and Technology, \\ Villupuram-607 107, Tamilnadu, India.
}

\author{
Dr.D.Mary \\ Principal \\ Government College of Engineering, \\ Burgur-635 104, Tamilnadu, India.
}

\begin{abstract}
To meet the growing load demand and provide reliable power supply, competition is introduced in the operation of electrical power market. In this scenario, the generators are submitting their energy bids in different time blocks. The market power for the corresponding load demand is determined from the submitted generators bids. In this paper, the total production cost for the corresponding load demand is determined from the generators bids and the corresponding power flow is demonstrated on 26 bus practical utility system. The obtained results proved that the proposed method is effective in the determining the generator operating settings from their submitted bids for the corresponding load demand.
\end{abstract}

Key Words- Competitive environment, Bids, Market power, Load demand.

\section{INTRODUCTION}

Bidding is the power trading procedure in which participants offer to buy energy and bids to sell energy directly in a restructured power market. It is the better bilateral trading of energy market than the existing markets like customized long term contracts, trading over the counter. All market participants can observe the quantities and prices submitted but do not know the identity of the party that submitted each bid or offer. When a party submits a new bid, the system that executes the exchange checks to see if there is a matching offer for the period of delivery of the bid. If it finds an offer whose price is greater than or equal to the price of the bid a deal automatically struck and the price and quantity are displayed for all participants to see. If no match is found, the new bid is added to the list of outstanding bids and will remain there until a matching offer is made or the bid is withdrawn or it lapses because the market closes for that period. A K David et al [1], discuss the framing of ground rules by system operators to prevent the bad use of the market by the participants in order to achieve their maximum profit. The different methods of bidding of strategic bid, multipart bid, single part bid, iterative bid and demand side bid are also explained in this literature review. Song et al [2], describe the importance of decision maker in the bidding process and his influence in the future market. Sometimes supplier's bid affect the spot price while others bidding level affected by the market price. To achieve optimal bidding strategy Markov decision process is proposed which is discrete state and time type. Plazas et al [3], describe the need of consideration of a thermal power producer in a sequence of spot market namely dayahead, automatic generation control (AGC) and balancing markets. A new stochastic programming methodology is proposed to determine the optimal bidding strategies for the day-ahead market. Conejo et al [4], describe the bidding strategy for price taker under price uncertainty in a pool-based electricity energy market also a modal has been proposed based the probability density functions of forecast prices. Bompared et al [5] explore the supply side strategic bidding in competitive electricity markets with network constraints impacts and demonstrated on IEEE 30 bus systems used as test system with perfect competition and strategic bidding techniques. A comprehensive approach has been used for modeling strategic bidding behavior under network constraints in a pool-based system. Analytical and numerical tools were used for assessing the impact of the constraints. Fututome et al [6] address the bidding market based on single price auction model with Ac network constraints for maximizing social surplus i.e. total profit of sellers and buyers. A standard IEEEJ WEST 30 test system was used with spot loads belonging to spot market and non spot loads such as bilaterally contracted customers and local utility supplied customers at the same time. In the papers [7\&8], the bidding strategy of a system is determined with inadequate information between the competitors in a multi trading market is solved by Watkins's reinforcement learning method. Many researchers [9-12], describe the leadership, the company with large generating capacity and low generating cost is named as leadership- Company and it may concentrate on gaining of additional profit. So market will be less efficient and it influences the optimal bidding strategies. Market power is the ability of a particular seller or group of sellers to maintain the price profitably above competitive level for the significant period of time. Overbye et al [13], give a brief idea about the prediction strategy of the market power in real time power systems.

In this paper, the total production cost for a particular load demand is computed from the optimized generator bids. The power flow is carried out by satisfying the transmission constraints. The validity of the proposed work is tested in 26 bus practical utility system.

\section{PROBLEM FORMULATION}

The minimum value of the generation production cost $\mathrm{C}_{\mathrm{t}}$ is determined by the equation (1).

$$
\text { Minimize } C_{t}=\sum_{i=1}^{N_{g}} C_{i}
$$

$\mathrm{C}_{\mathrm{t}}$-Total bidding cost of generation ( $\mathrm{Rs} / \mathrm{hr}$ ).

$\mathrm{C}_{\mathrm{i}}$-Bidding cost of $\mathrm{i}^{\text {th }}$ generator.

$\mathrm{N}_{\mathrm{g}}$-Number of generators.

The above objective function satisfies the following constraints. The power balance equation is given by

$$
\mathrm{g}|\mathrm{v}|, \theta=0
$$

Where 


$$
\begin{aligned}
& \mathrm{g}|\mathrm{v}|, \theta=\left|\begin{array}{ccc}
\mathrm{P}_{\mathrm{i}} & |\mathrm{v}|, \theta & -\mathrm{P}_{\mathrm{i}}^{\text {net }} \\
\mathrm{Q}_{\mathrm{i}} & |\mathrm{v}|, \theta & -\mathrm{Q}_{\mathrm{i}}^{\text {net }} \\
\mathrm{P}_{\mathrm{m}} & |\mathrm{v}|, \theta & -\mathrm{P}_{\mathrm{i}}^{\text {net }}
\end{array}\right| \\
& \mathrm{P}_{\mathrm{i}} \& \mathrm{Q}_{\mathrm{i}} \rightarrow \text { Calculated real and reactive power } \\
& \text { for PQ bus i. } \\
& P_{i}^{\text {net }} \& Q_{i}^{\text {net }} \rightarrow \text { Specified real and reactive power } \\
& \text { for PQ bus i. } \\
& \mathrm{P}_{\mathrm{m}} \& \mathrm{P}_{\mathrm{m}}^{\text {net }} \rightarrow \text { Calculated and specified real } \\
& \text { power for PV bus } \mathrm{m} \text {. } \\
& |\mathrm{v}| \& \theta \rightarrow \text { Voltage magnitude and phase angle } \\
& \text { of different buses. } \\
& \left.\mathrm{P}_{\mathrm{i}}|\mathrm{v}|, \theta-\mathrm{P}_{\mathrm{i}}^{\text {net }}\right\} \rightarrow \text { For each PQ bus i. } \\
& \left.\mathrm{Q}_{\mathrm{i}}|\mathrm{v}|, \theta-\mathrm{Q}_{\mathrm{i}}^{\text {net }}\right\} \\
& \mathrm{P}_{\mathrm{m}}|\mathrm{v}|, \theta-\mathrm{P}_{\mathrm{i}}^{\text {net }} \rightarrow \text { For each } \mathrm{PV} \text { bus } \mathrm{m} \text {, not including } \\
& \text { the reference bus. }
\end{aligned}
$$

- The inequality constraint on real power generation $\mathrm{P}_{\mathrm{gi}}$ of each generation

$$
\mathrm{P}_{\mathrm{gi}}^{\min } \leq \mathrm{P}_{\mathrm{gi}} \leq \mathrm{P}_{\mathrm{gi}}^{\max }
$$

$\mathrm{P}_{\mathrm{gi}}^{\min } \& \mathrm{P}_{\mathrm{gi}}^{\max } \rightarrow$ Minimum and maximum value of real power allowed at generator $\mathrm{i}$.

- The inequality constraint on voltage of each PQ bus $i$

$$
\mathrm{V}_{\mathrm{t}}^{\min } \leq \mathrm{V}_{\mathrm{t}} \leq \mathrm{V}_{\mathrm{t}}^{\max }
$$

$\mathrm{V}_{\mathrm{t}}^{\mathrm{min}} \& \mathrm{~V}_{\mathrm{t}}^{\mathrm{max}} \rightarrow$ Minimum and maximum voltage at bus i.

- $\quad$ Power limit on transmission line

$$
\operatorname{MVAf}_{\mathrm{p}, \mathrm{q}} \leq \mathrm{MVAf}_{\mathrm{p}, \mathrm{q}}^{\max }
$$

$\mathrm{MVAf}_{\mathrm{p}, \mathrm{q}}^{\max } \rightarrow$ Maximum rating of transmission line connecting bus $\mathrm{PQ}$.

\section{STEP - BY - STEP ALGORITHM}

The proposed algorithm to determine the production cost of generators from their bids is explained as follows.

- $\quad$ Obtain the bidding data of the corresponding generators in each block.

- $\quad$ Sketch the consolidated bidding curve of the generators obtained from the optimized bidding data in each block. This gives an overall idea about the contribution of generators in each block of load demand of the above generators.

- Obtain the generators settings for the different load demand from the above bidding curve.

- $\quad$ Obtain the power solution of the above generators setting by satisfying the transmission line constraints.

- Compute the total production cost for the different case studies.

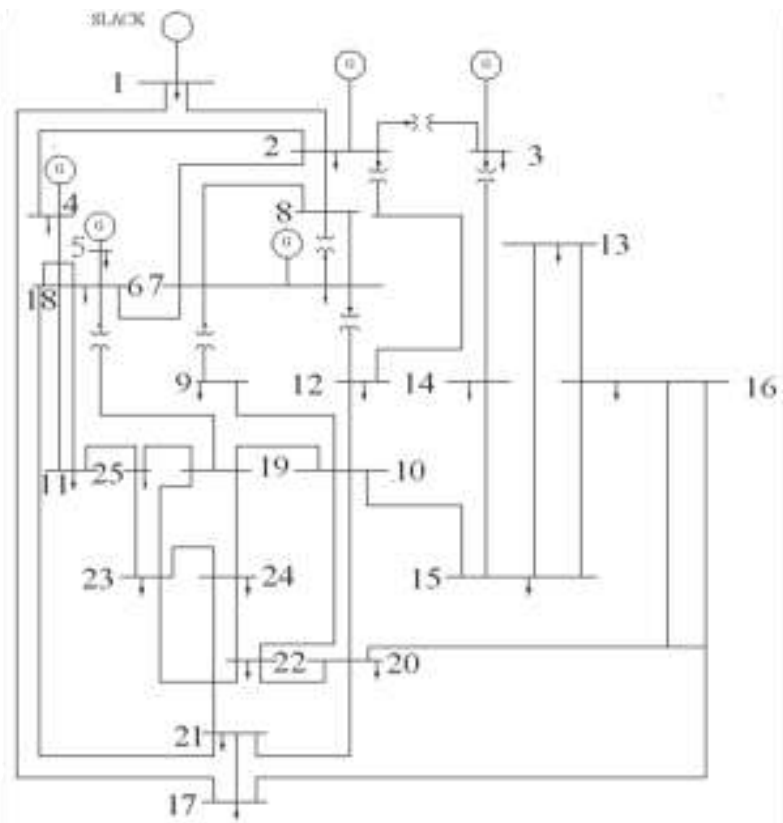

Figure 1. One line diagram - 26 Bus System

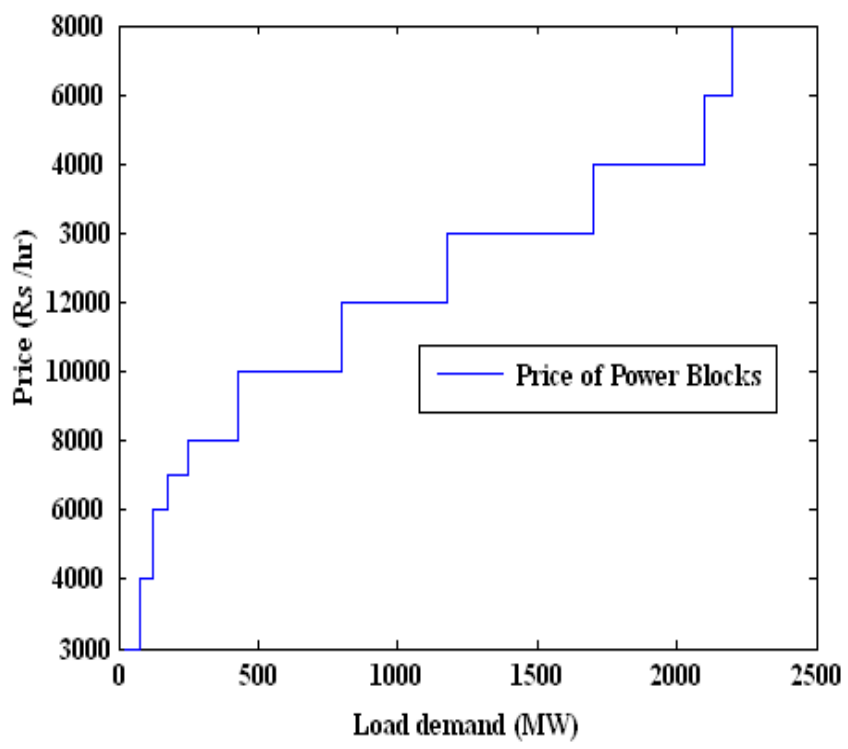

Figure 2. Bidding Curve of Generators

\section{SIMULATION RESULTS AND DISCUSSION}

The bid based optimal generation cost is computed by executing the bid based power flow algorithm in the MATLAB environment. The proposed methodology was demonstrated on the practical 26 bus utility system [14]. Its one line diagram is given in Fig. 1. It consists of 6 generators, 46 numbers of $220 \mathrm{KV}$ transmission lines and 7 tap changing transformer. The generator settings are obtained from the bidding blocks of the corresponding generators for a particular load demand. The power flows in the transmission lines are computed using Newton Rahpson method. The bidding based power flow solution is 
demonstrated on the above utility system with the following case studies.

1. Base load condition

2. Increased in load condition

3. Critical load condition

Case study 1: Base load condition

The 26 bus utility system is subjected to the base load demand of $1000 \mathrm{MW}$. The bidding data of the each generator are given in Appendix. The bidding curve is formulated by arranging the optimized bids of corresponding generator in each block. The generators settings for the base load condition are obtained from the submitted generator bids and same is illustrated in Fig.2. The load flow solution for the test system is obtained using the above generator settings for the base load demand.

Case study 2: Increased in load condition

To illustrate the efficiency the proposed methodology, the load demand of the test system is increased to $1800 \mathrm{MW}$ and the corresponding power flow solution is obtained using the respective generator contribution as given in Fig.2. The obtained power flow solutions satisfy the thermal limit of the transmission lines as illustrated in Fig.3.

Case study 3: Critical load condition

There is an ambiguity in the computation of cost when the bids are switched from one block state to another as given in Fig.2. The load demand at this switched state is termed as critical load in this work. In this critical load condition, the bidding cost of the committed generators are taken as the half the values in the corresponding blocks. The production cost is computed by taking the above optimized price approach. The production cost of each generator for the above case studies is given in the Fig. 4. The consolidated bid based generator's settings and the production cost for above three case studies is given in Table 1 .

\section{CONCLUSIONS}

The paper demonstrated the generator bid based power flow solution of a practical utility system with different case studies. The obtained solution gives over all idea about the computation of production cost from the generator bids of the competitive environment. It also illustrates the computation of production cost when the generator bids shift from one block to another. The power flow solution is obtained by Newton Raphson method by satisfying the constraints. In a nutshell, this paper gives knowledge about the prediction of total production cost of the system form the bidding structure of generators for the corresponding load demand.

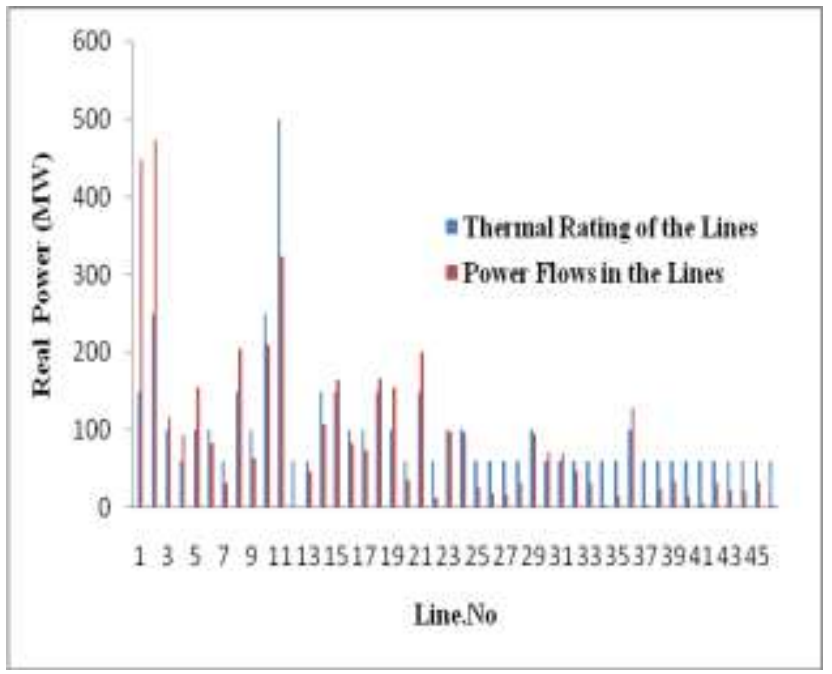

Figure 3. Power flows in the transmission lines

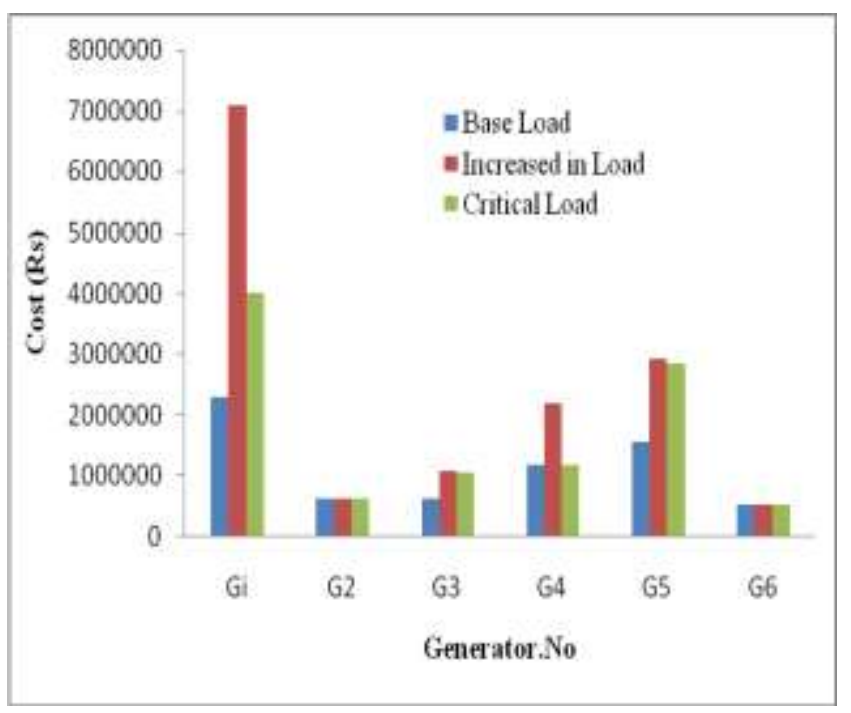

Figure 4. Total Production Cost

Table 1. Power dispatch Solutions for different case studies

\begin{tabular}{|c|c|c|c|c|c|c|c|c|}
\hline \multirow{2}{*}{ Load Demand } & \multicolumn{6}{|c|}{ Contribution of Generators $(\mathbf{M W})$} & \multirow{2}{*}{ Total Cost (Rs/hr) } & $\begin{array}{c}\text { Total Loss } \\
\text { (MW) }\end{array}$ \\
\cline { 2 - 9 } & $\mathbf{G}_{\mathbf{1}}$ & $\mathbf{G}_{\mathbf{2}}$ & $\mathbf{G}_{\mathbf{3}}$ & $\mathbf{G}_{\mathbf{4}}$ & $\mathbf{G}_{\mathbf{5}}$ & $\mathbf{G}_{\mathbf{6}}$ & & 7.960 \\
\hline Base load & 300 & 100 & 100 & 200 & 225 & 75 & 6837500 & 27.213 \\
\hline Increased in load & 800 & 100 & 150 & 300 & 375 & 75 & 14437500 & 15.296 \\
\hline Critical load & 500 & 100 & 150 & 200 & 375 & 75 & 10237500 & \multirow{2}{*}{${ }^{*}$} \\
\hline
\end{tabular}




\section{REFERENCES}

[1] A.K. David and F.Wen,"Strategic bidding in competitive electricity market: A literature survey," in Proceedings of IEEE PES 2000 Summer Meeting, Seattle, July 15-20, 2000.

[2] Haili Song Chen-Ching Liu,Jacques Lawarree and Robert W.Dahlgren,“" Optimal Electricity Supply Bidding by Markov Decision Process", IEEE Transaction on Power System Vol.15 no.2 May 2000.

[3] Miguel A.Plazas,Antonio J. Conejo, and Francisco J. Prieto, "Multi Market Optimal Bidding For A Power Producer", IEEE Transaction on Power System Vol.20 no.4 May 2005.

[4] Antonio J. Conejo, Francisco Javier Nogales, and Joes Manuel Arroyo, "Price-Taker Bidding Strategy under Price Uncertainty", IEEE Transaction on Power System Vol.17 no.4 November 2002.

[5] Ettore Bompared, Wene $\mathrm{Lu}$ and Roberto Napoli, "Network Constraint Impacts On The Competitive Electricity Market Under Supply- Side Strategic Bidding", IEEE Transaction on Power System Vol.21 no.1 February 2006.

[6] Suguru Fukutome, Tsunehisa Wachi, Luonan Chen, Yoshinori Makino and Gentarou Koshimizu, "Bidding Market Based on Single Price Model With Network Constraints”, IEEE PES 2004.

[7] Yuchao ma, Ettore F. Bompared, Roberto Napoli and Jiang Chuanwen, "Modeling the Strategic Bidding of the Producers in Competitive Electricity Markets with the Wakins's Q (lambda) Reinforcement Learning", International Journal of Emerging Electric Power System Vol.6 issue 2, 2006, article 7

[8] T.Chandarasupsang, S. Galloway, G.Burt, J.Mc.Donald and T.Siewierski, "Bidding behavior and Electricity Market Simulation", European Transactions on Electrical Power published On-Line $4^{\text {th }}$ April 2007 in Wiley Inter Science.

[9] H.He, Z.Xu, and C.Wang, "Analysis of Bidding Strategy for Leadership - Company in Power Market”, IEEE PES 2004.
[10] Q.H.Wu, J.Guo, D.R.Turner, Z.X.Wu, X.X.Zhou, “Optimal Bidding Strategies in Electricity Markets Using Reinforcement Learning", Electric Power Components and Systems, Vol.32, no.175-192, 2004.

[11] Youfei Liu and Felix F.Wu, "Generator Bidding in Oligopolistic Electricity Markets Using Optimal Controls: Fundamentals and Applications", IEEE Transaction on Power Systems, vol.21, no. 3, August 2006.

[12] H.Zhou , J.H.Chen, X.H.Xiong, F.Q.Zhang, Z.X.Han and W.Z.Sun, "A Novel Approach to Evaluate the Variation of Power Producer's Bidding Curves based on Dimensional Reduction Model", European Transactions on Electrical Power, Published On-Line $18^{\text {th }}$ September 2007 in Wiley Inter Science.

[13] Thomas J.Overbye, Kollin Patten, “Assessment of Strategic Market Power in Power System”, IEEE PES 1998.

[14] Hadi saadat "Power system analysis", Tata McGraw Hill Publication, edition 2002.

\section{BIOGRAPHIES}

C.Venkatesan received the B.E from Madras University in 2002 and M.E from Annamalai University in 2007. He currently pursues the Ph.D. Degree in Anna University of Technology, Coimbatore and Tamilnadu. At present he is working as Assistant Professor in V.R.S College of Engineering and Technology Villupuram, Tamilnadu, India. His fields of interest are Power system analysis, Intelligent Techniques and Deregulation. He is member in IEEE.

Dr.D.Mary received the Ph.D. degree from Bharathiyar University, Tamilnadu, India in 2002.At present she is working as Principal at Government College of Engineering, Bargur, and Tamilnadu, India. Her fields of interest are Power system, Control $\&$ Instrumentation and Intelligence Techniques. She has published more than 48 technical papers in leading journals. 


\section{APPENDIX}

\section{BIDDING DATA OF THE GENERATORS}

\begin{tabular}{|c|c|c|}
\hline \multicolumn{3}{|c|}{ Generator $\mathrm{G}_{1}(100-1000 \mathrm{MW})$} \\
\hline Block & Quantity $(\mathrm{MW})$ & Cost (Rs/MW) \\
\hline $0-100$ & 100 & 7000 \\
\hline $100-300$ & 200 & 8000 \\
\hline $300-500$ & 200 & 9000 \\
\hline $500-800$ & 300 & 10000 \\
\hline $800-1000$ & 200 & 11000 \\
\hline
\end{tabular}

\begin{tabular}{|c|c|c|}
\hline \multicolumn{3}{|c|}{ Generator $\mathrm{G}_{4}(0-300 \mathrm{MW})$} \\
\hline Block & Quantity (MW) & Cost (Rs/MW) \\
\hline $0-50$ & 50 & 4000 \\
\hline $50-75$ & 25 & 5500 \\
\hline $75-150$ & 75 & 6000 \\
\hline $150-200$ & 50 & 8000 \\
\hline $200-300$ & 100 & 10000 \\
\hline
\end{tabular}

\begin{tabular}{|c|c|c|}
\hline \multicolumn{3}{|c|}{ Generator $\mathrm{G}_{2}(0-100 \mathrm{MW})$} \\
\hline Block & Quantity $(\mathrm{MW})$ & Cost ( Rs/MW) \\
\hline $0-50$ & 50 & 5000 \\
\hline $50-75$ & 25 & 7000 \\
\hline $75-100$ & 25 & 8000 \\
\hline
\end{tabular}

\begin{tabular}{|c|c|c|}
\hline \multicolumn{3}{|c|}{ Generator $\mathrm{G}_{5}(0-600 \mathrm{MW})$} \\
\hline Block & Quantity $(\mathrm{MW})$ & Cost (Rs/MW) \\
\hline $0-75$ & 75 & 6000 \\
\hline $75-175$ & 100 & 7000 \\
\hline $175-250$ & 75 & 8000 \\
\hline $250-400$ & 150 & 9000 \\
\hline $400-500$ & 100 & 10000 \\
\hline $500-600$ & 100 & 12000 \\
\hline \multicolumn{3}{|c|}{ Generator $\mathrm{G}_{6}(0-75 \mathrm{MW})$} \\
\hline Block & Quantity (MW) & Cost (Rs/MW) \\
\hline $0-25$ & 25 & 5000 \\
\hline $25-50$ & 25 & 7000 \\
\hline $50-75$ & 25 & 9000 \\
\hline
\end{tabular}

\begin{tabular}{|c|c|c|}
\hline \multicolumn{3}{|c|}{ Generator $\mathrm{G}_{3}(0-150 \mathrm{MW})$} \\
\hline Block & Quantity (MW) & Cost (Rs/MW) \\
\hline $0-25$ & 25 & 3000 \\
\hline $25-75$ & 50 & 7000 \\
\hline $75-100$ & 25 & 8000 \\
\hline $100-150$ & 50 & 9000 \\
\hline
\end{tabular}

